Article

\title{
Effect of Bitumen Emulsion and Polyester Resin Mixture on the Physico-Mechanical and Degradable Properties of Jute Fabrics
}

\author{
Nasrin Akter ${ }^{1,2}$, Joykrisna Saha ${ }^{2}$, Subrata Chandra Das ${ }^{2,3, *}$ and Mubarak Ahmad Khan ${ }^{4}$ \\ 1 Department of Textile Engineering, Ahsanullah University of Science and Technology, \\ Dhaka 1215, Bangladesh; nasrinakter.luna@gmail.com \\ 2 Department of Textile Engineering, Mawlana Bhashani Science and Technology University, \\ Tangail 1902, Bangladesh; joykrishnakaratia@yahoo.com \\ 3 Bangabandhu Textile Engineering College, Department of Textiles, Ministry of Textiles and Jute, \\ Tangail 1970, Bangladesh \\ 4 Institute of Radiation and Polymer Technology, Atomic Energy Research Establishment, Bangladesh Atomic \\ Energy Commission, Savar, Dhaka 1349, Bangladesh; makhan.inst@gmail.com \\ * Correspondence: sc.das_mbstu@yahoo.com; Tel.: +88-017-103-37874
}

Received: 16 April 2018; Accepted: 13 June 2018; Published: 25 June 2018

\begin{abstract}
Jute fabrics were treated, with different formulations, using various proportions of bitumen emulsion and polyester (PE) resin in combined solutions. Styrene monomer was used as solvent, methyl ethyl ketone peroxide as cross-linking agent and cobalt naphtha as curing agent. The fabric specimens were immersed in the solution for 10-15 $\mathrm{min}$, then pressed by a roller and dried at room temperature for $24 \mathrm{~h}$. According to the percentage of bitumen emulsion and PE resin, the jute samples were obtained as $\mathrm{J} 0$ (untreated or raw jute), J1 (20\% bitumen emulsion $+10 \% \mathrm{PE}$ ), and J2 ( $10 \%$ bitumen emulsion $+20 \%$ PE). It was revealed that tensile strength (TS) increased with bitumen emulsion and PE resin mixture treatment on both directions of jute fabrics where J2 showed the highest improvement of TS which were $61.4 \%$ and $44.7 \%$ for warp and weft direction respectively. Tensile strength (TS) decreased for all the samples in both directions after soil degradation. After 90 days, the untreated sample was totally degraded. Treated samples exhibited better stability than untreated ones in soil medium. Weight loss by soil degradation, moisture regain, moisture content and water uptake tests of the treated and untreated jute samples were also performed. Scanning electron microscopy (SEM) analysis was conducted to analyze the fiber surfaces of raw and treated jute fibers, finding significant differences as a result of treatment. Finally, the strategy of combining bitumen emulsion and PE resin for treatment, rather than using only PE resin, was found to produce a jute fabric which was not only better in all the above respects but also would be cheaper to produce.
\end{abstract}

Keywords: bitumen emulsion; polyester resin; jute fabric; tensile strength; soil degradation

\section{Introduction}

Jute is the most important natural cellulose-based fiber, second only to cotton, in world natural fiber production. Bangladesh and India dominate the world jute market, as more than $85 \%$ of the world's jute fibers are grown in these two countries [1]. The main constituents of jute are cellulose $(58-60 \%)$, hemicellulose (21-25\%), lignin (12-14\%), fats and waxes $(0.4-1.0 \%)$. Other minor ingredients such as proteins or nitrogenous matters, pectins, mineral matters, and traces of pigments are present in jute [2-4]. Jute fibers possess many promising characteristics such as light weight and sufficient strength. Jute is also ecofriendly, cheap, abundant, and convenient to process. Among natural fibers, jute has the longest staple length as well as outstanding properties for textile utilizations. Among the 
natural fibers, jute is extensively employed in manufacture of sacks, packaging, carpet backings, furnishing fabrics and composite materials etc. [5,6]. Basically, jute is a $100 \%$ biodegradable fiber, hydrophilic in nature. The degradation process can be made quicker by various factors such as moist environment, immersion in water, the influence of bacteria, mildew, fungi, insects, etc. Jute is also not sustainable in certain chemical media. Jute is generally swollen in contact with water and destroyed if it is exposed for six months to water. This inherent drawback of jute fiber can be overcome by several techniques and methods of chemical treatment [7-15]. Saha et al. reported that jute fabrics treated with $5 \%, 10 \%, 15 \%, 20 \%$ and $25 \%$ polyester (PE) resin showed improved physico-mechanical features. Jute treated with $25 \%$ PE resin showed the best result. However, tensile strength (TS) decreased 34\% for raw jute. On the other hand, TS decreased by $8 \%$ where the samples had been treated with $25 \%$ resin, after 42 days buried under the soil [16].

Bitumen emulsion is a dispersed liquid consisting of three products: water, bitumen, and emulsion. Bitumen (asphalt in USA) is generally used for road construction [17-19]. Various applications of bitumen emulsion were also observed [20-23]. D. Kar studied sisal fiber treated with SMA (Stone Matrix Asphalt) and bituminous concrete (BC) composite and found that $5 \%$ bituminous concrete (BC) and 5.2\% SMA (Stone Matrix Asphalt) combination with $0.3 \%$ fiber content produced the best results [24]. Dynamic modulus, moisture susceptibility, and permanent deformation properties were improved by the application of hot asphalt mixtures to fibers [23,25-27]. In view of these studies, showing significant improvement of fiber results with the application of bitumen emulsion, we have formed the hypothesis that adding bitumen emulsion to the widely-used PE resin will significantly improve the physico-mechanical properties of jute. Polyester resin is a widely-used polymer matrix employed with natural and synthetic fibers around the world. It is a thermoset polymer and possesses many useful characteristics for instance curing at room temperature and suitable mechanical properties. The incorporation of $\mathrm{PE}$ resin with various cellulose-based natural fibers has been reported by different researchers such as PE-jute [28-30], PE-sisal [31-33], PE-coir [34-36], PE-ramie [37], PE-pineapple leaf [38-40], PE-hemp [41], and PE-cotton-kapok [42]. PE can also be reinforced with synthetic fibers $[43,44]$.

Thus, this paper analyzes the combined effect of applying bitumen emulsion and PE resin solution, together, to jute fabrics. Our hypothesis, as stated above, suggests that adding bitumen emulsion will significantly improve even these results. Yet there are far better reasons to try this method. PE resin is costlier than bitumen emulsion. Adding bitumen emulsion can substitute out some of the PE, thereby reducing the cost of treatment of the fabrics. In addition, bitumen emulsion is more easily available, as well as cheap, ecofriendly and has rutting resistance properties. Therefore, using bitumen emulsion with PE resin together, in jute fabrics, would be a cost-effective technique with additional physico-mechanical benefits to the fabric and will make treatment easier as well as cheaper and better.

The major aim of the research is to study the effects of bitumen emulsion and PE resin on the physico-mechanical and degradation properties jute fabrics.

\section{Materials and Methods}

\subsection{Materials}

Jute woven fabric $(1 \times 1$ plain weave, 15 EPI and 15 PPI $)$ was collected from the Jute Diversification Promotion Centre (JDPC), Dhaka. Scouring, bleaching, and dyeing were not done in this fabric. Bitumen emulsion, styrene monomer, unsaturated polyester (PE) resin, methyl ethyl ketone peroxide (MEKP) and cobalt naphtha were collected from local agent. All the chemicals and reagents were purchased as laboratory grade and used without any purification. 


\subsection{Methods}

\subsubsection{Sample Preparation}

Raw jute fabrics were treated with bitumen emulsion and unsaturated polyester (PE) resin. The chemical solution was prepared by mixing different percentages of PE resin with bitumen emulsion as shown in Table 1. In this solution, styrene monomer was used as a solvent, 5\% MEKP was used as a cross linking agent and 1 to 2 drops $(0.1-0.5 \mathrm{~mL})$ of cobalt naphtha was used as a curing agent for every sample. Then the jute fabric was dipped in the solution for 10-15 min and after that the fabric was pressed by a roller and dried at room temperature for $24 \mathrm{~h}$. In this experiment, J0 (untreated or raw jute), J1 (20\% bitumen emulsion and 10\% PE resin) and J2 (10\% bitumen emulsion and 20\% PE resin) samples were obtained by this process as laid out in Table 1 below, and for J1 and J2 samples, $70 \%$ fiber weight $\%$ were taken.

Table 1. Sample formulation.

\begin{tabular}{ccc}
\hline Sample & Bitumen Emulsion (\%) & Polyester Resin (\%) \\
\hline J0 & 0 & 0 \\
J1 & 20 & 10 \\
J2 & 10 & 20 \\
\hline
\end{tabular}

\subsubsection{Mechanical Testing of the Sample}

\section{Tensile Test}

The TS of the specimens were measured according to ASTM D 5035 (Grab test). The test sample was cut $152.4 \mathrm{~mm} \times 101.6 \mathrm{~mm}$ in both warp and weft directions. The sample was clamped in top and bottom jaw. Pressure of clamping was optimum so that it does not slippage and breaks at the back of the jaws. Then the machine was started, and pretension was optimum. The machine works at a constant rate of extension (CRE) of $100 \mathrm{~mm} / \mathrm{min}$, until it reaches a breakpoint at cell load $3000 \mathrm{~N}$. The same procedure was performed 5 times, in both the warp and weft directions and the average result was reported.

\section{Soil Degradation Test}

Treated and untreated samples were buried in soil up to 90 days. After 15, 45 and 90 days, samples were carefully withdrawn from the soil, washed lightly with distilled water, and dried at room temperature for $24 \mathrm{~h}$. Then, each time, the tensile strength of the fabric was determined [45].

\section{Determination of Mass for Unit Area}

The mass for unit area of the samples was determined according to ASTM-D3776. The test sample was cut by a GSM cutter, which was $100 \mathrm{~cm}^{2}$. The sample was then conditioned in standard atmosphere before being weighed. Weight was assessed after conditioning. This procedure was performed three times, from which an average result was reported.

\section{Determination of Moisture Regain and Content}

Moisture regain is the percentage of moisture in a textile material brought into equilibrium within a standard atmosphere after partial drying. Moisture regain is calculated by the following formulae

$$
\text { Moisture Regain }(M R)=\frac{W}{D} \times 100 \%
$$


The moisture content of textile materials when they are in equilibrium with their surroundings is determined by the amount of moisture in the air. Moisture Content is measured by the following equation

$$
\text { Moisture Content }(\mathrm{MC})=\frac{\mathrm{W}}{\mathrm{W}+\mathrm{D}} \times 100 \%
$$

where, $\mathrm{W}=$ Weight of water $(\mathrm{A}-\mathrm{D}), \mathrm{A}=$ Weight of the sample before drying, $\mathrm{D}=$ Moisture free weight after drying.

MR and MC are based on moisture-free weight. Moisture-free weight means the constant weight of a specimen obtained by drying at a temperature of $105^{\circ} \mathrm{C}$ in an electric current until desiccated [46].

Water Absorbency Test

The first step was to condition the samples $(5 \mathrm{~cm} \times 5 \mathrm{~cm})$ and weighed them. Then the samples were immersed in distilled water at a temperature of $25^{\circ} \mathrm{C}$ for $60 \mathrm{~min}$. After a certain time, the samples were then taken out of the immersion and excess water was removed by using tissue paper. According to British Standard 3449, the water absorbency test was performed [47]. The water absorption was calculated as

$$
\text { Water absorption }(\%)=\frac{\text { Mass of water absorbed }}{\text { Orginal mass }} \times 100
$$

\section{Scanning Electron Microscopy}

The surface morphology of the treated and untreated samples was identified by the scanning electron microscopy (SEM) (JSM-6490 LA, JEOL, Tokyo, Japan). The test was carried out with a maximum operating range of $20 \mathrm{kV}$, using the apparatus in the Center for Advanced Research in Science (CARS), University of Dhaka, Bangladesh. The scanning electron microscope took the picture of the sample surface by scanning it with a high energy beam of electrons. The electrons interact with the atoms that make up the sample, producing signals that contain information about the sample's surface topography. Surface micrographs were taken at a magnification of $\times 30, \times 50$ and $\times 100$, with a scale of $500 \mu \mathrm{m}$ and $100 \mu \mathrm{m}$.

\section{Results and Discussion}

The jute fabric samples used in this experiment are shown in Figure 1. The treated sample is shown in Figure 1a which was J2 (10\% bitumen emulsion and 20\% PE resin). After 15 days of soil burial test the treated sample is shown in Figure 1b; Figure 1c,d represent the samples after 45 and 90 days of soil burial test respectively. The untreated or raw jute fabric (J0) after 45 days of soil degradation test is exhibited in Figure 1e.

A comparison was observed of the treated and untreated jute fabrics after the soil degradation test in Figure 1. After 15 days, there is no difference found on the treated samples. After 45 days, slightly degradation found in the treated samples in Figure 1c, and more degradation is found in untreated sample after 45 days as shown in Figure 1e. Figure 1d shows the degradation of treated jute fabric after 90 days i.e., this sample can be used for any application require for 90 days or more such as gardening, cultivation, or any other geo-textile applications, whereas after 90 days no traces is found for untreated jute sample. 


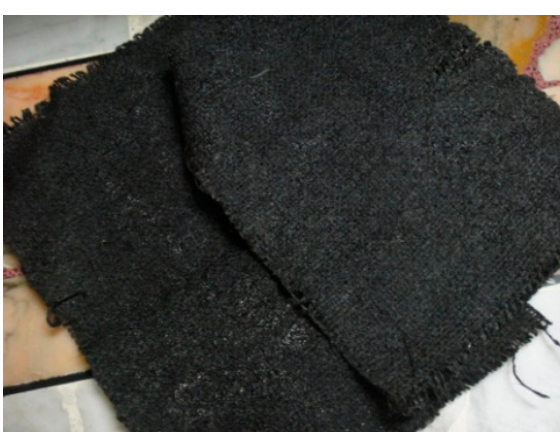

(a)

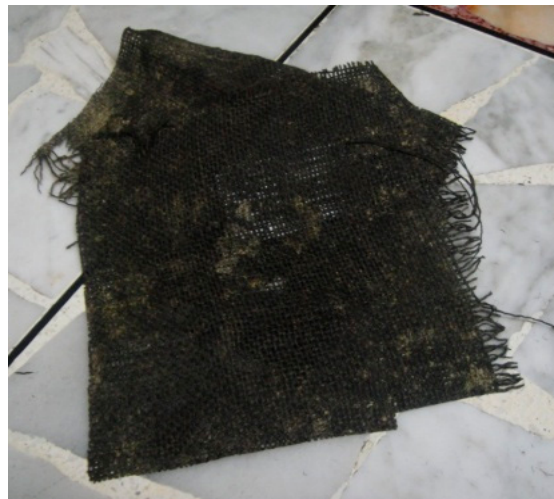

(c)

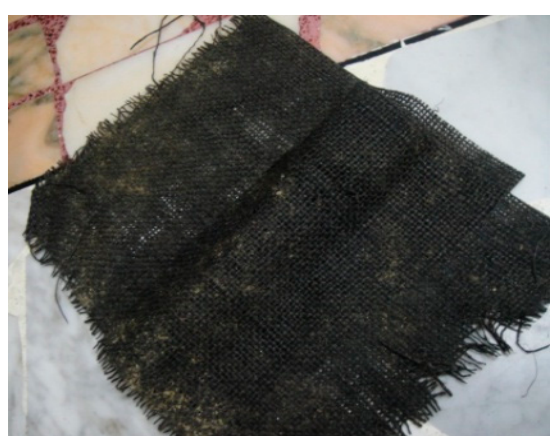

(b)

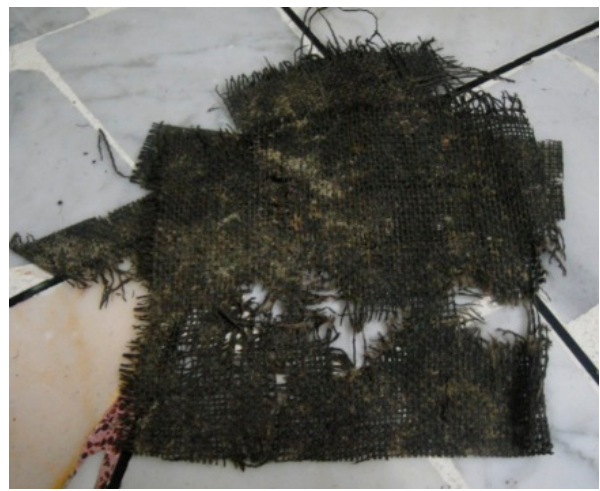

(d)

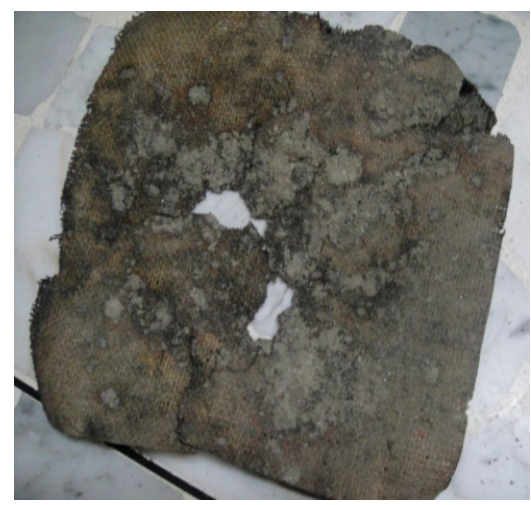

(e)

Figure 1. Jute fabric used in the experiment: (a) treated jute fabric; (b) treated jute fabric after 15 days; (c) treated jute fabric after 45 days; (d) treated jute fabric after 90 days; (e) untreated jute fabric after 45 days.

In this Figure, one can see graphically the extent of degradation exhibited by jute fabric left in soil for an extended period. It is easy to compare, even by sight, the relative strength, to see the effects of treatment in reducing degradation.

\subsection{Tensile Strength}

Figure 2 shows the TS of J0 (untreated), J1 and J2 specimens are 411.8, 431.8 and $664.8 \mathrm{~N}$, respectively in warp direction and $372.4,392.0$ and $539.0 \mathrm{~N}$, respectively in weft direction. It is revealed that TS increased after bitumen emulsion and resin mixture treatment in both directions of jute fabrics. In warp direction, TS increased $4.9 \%$ and $61.4 \%$ for $\mathrm{J} 1$ and $\mathrm{J} 2$ samples respectively, and in weft direction, TS increased 5.3\% and 44.7\% for J1 and J2 samples respectively as shown in Figure 2. The highest increase of TS found for J2 which was produced by $10 \%$ bitumen emulsion and $20 \% \mathrm{PE}$ resin treatment. Due to the maximum amount of PE resin having been used (20\%) for J2, plus the 
addition of bitumen emulsion, the fabric exhibited the highest TS. Saha et al. reported that when jute fabrics were treated with $5 \%, 10 \%, 15 \%, 20 \%$ and $25 \%$ PE resin only, the TS increased from $3.5 \%$ to $18.8 \%$, compared to untreated jute fabric, respectively [16]. In our previous study [16], TS increased $16.6 \%$ for only $20 \%$ PE resin treatment; but in this study, TS increased $44.7 \%$ for $\mathrm{J} 2(20 \%$ PE $+10 \%$ bitumen emulsion) which showed that TS increased more than 2.5 times. Therefore, the effect of bitumen emulsion is clear.

The bitumen emulsion and polyester resin both are polymers which most probably did not reacted with jute fibers. As bitumen emulsion is highly adhesive in nature, it created coating or physical bonding with jute fibers, which will give improved mechanical properties to jute fabrics. Similarly, polyester resin also built coating around the jute fiber surface and increases its mechanical properties. Improved physico-mechanical properties of the sample will be achieved if the interfacial adhesion between jute fibers and these two polymers are occurred. To do so, fibers must be properly soaked into the polyester and bitumen emulsion solution. In addition, pressure is needed for better penetration of the solution mix into the fibers and to remove voids inside the fibers.

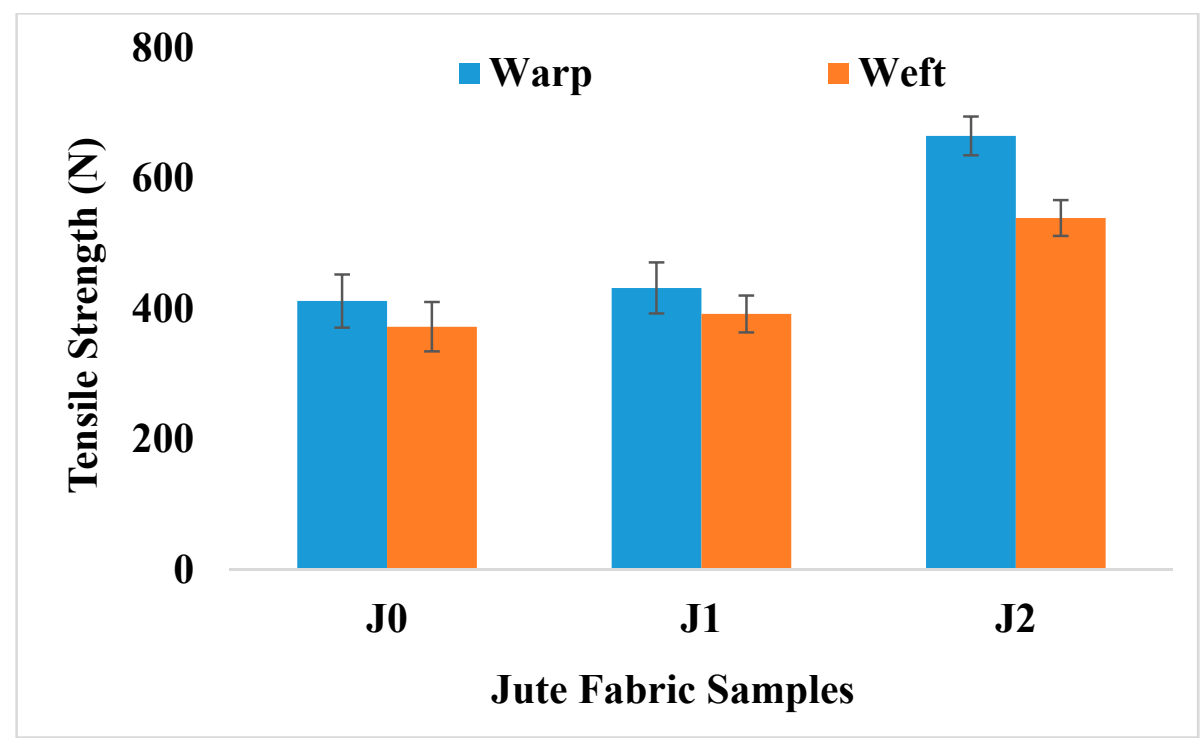

Figure 2. Tensile strength of the jute samples in warp and weft directions.

\subsection{Tensile Strength Loss by Soil Degradation}

TS of the jute fabrics were measured during soil degradation after 15, 45 and 90 days in warp and weft direction. After 15, 45 and 90 days, TS was 196.0, 68.6 and $0 \mathrm{~N}$ respectively for J0 fabrics in warp direction. Similarly, after 15, 45 and 90 days, TS was found to be 294.0, 98.0 and $39.2 \mathrm{~N}$ for J1, and 333.2, 137.2 and $49.0 \mathrm{~N}$ for J2 fabrics respectively in warp direction as shown in Figure 3. For untreated jute fabric (J0), after 90 days TS was not found due to degradation of jute fabric in soil. After 15 days, loss of TS found to be $52.4 \%, 31.9 \%$ and $49.9 \%$ for J0, J1 and J2 fabrics respectively. Similarly, after 45 days and 90 days, TS reduced to be $83.3 \%, 77.3 \%, 79.4 \%$, and $100 \%, 90.9 \%, 92.6 \%$ respectively for J0, J1, $\mathrm{J} 2$ fabrics in warp direction. After 15, 45 and 90 days, TS was 147.0, 39.2 and $0 \mathrm{~N}$ respectively for J0 fabrics in weft direction. Similarly, after 15, 45 and 90 days, TS was found to be 196.0, 49.0 and $9.8 \mathrm{~N}$ for J1, and 196.0, 78.4 and $19.6 \mathrm{~N}$ for J2 fabrics respectively in weft direction as shown in Figure 4. 


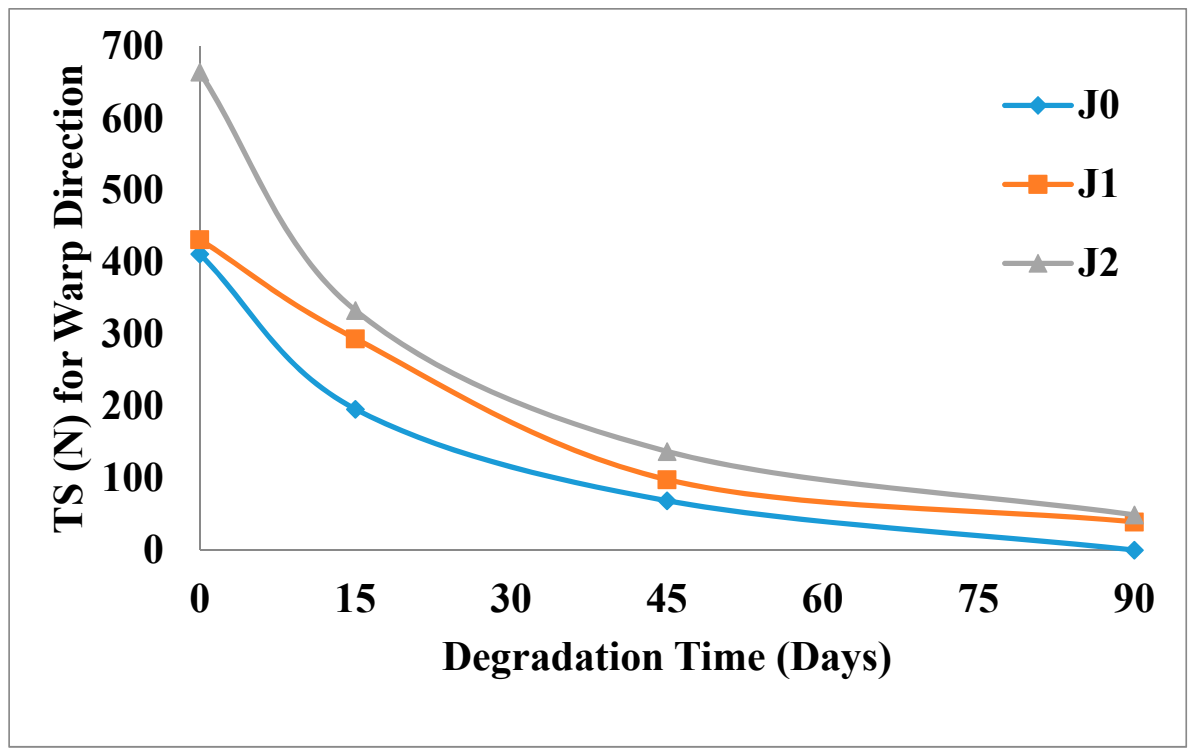

Figure 3. Loss of tensile strength of jute fabrics in warp direction during soil degradation.

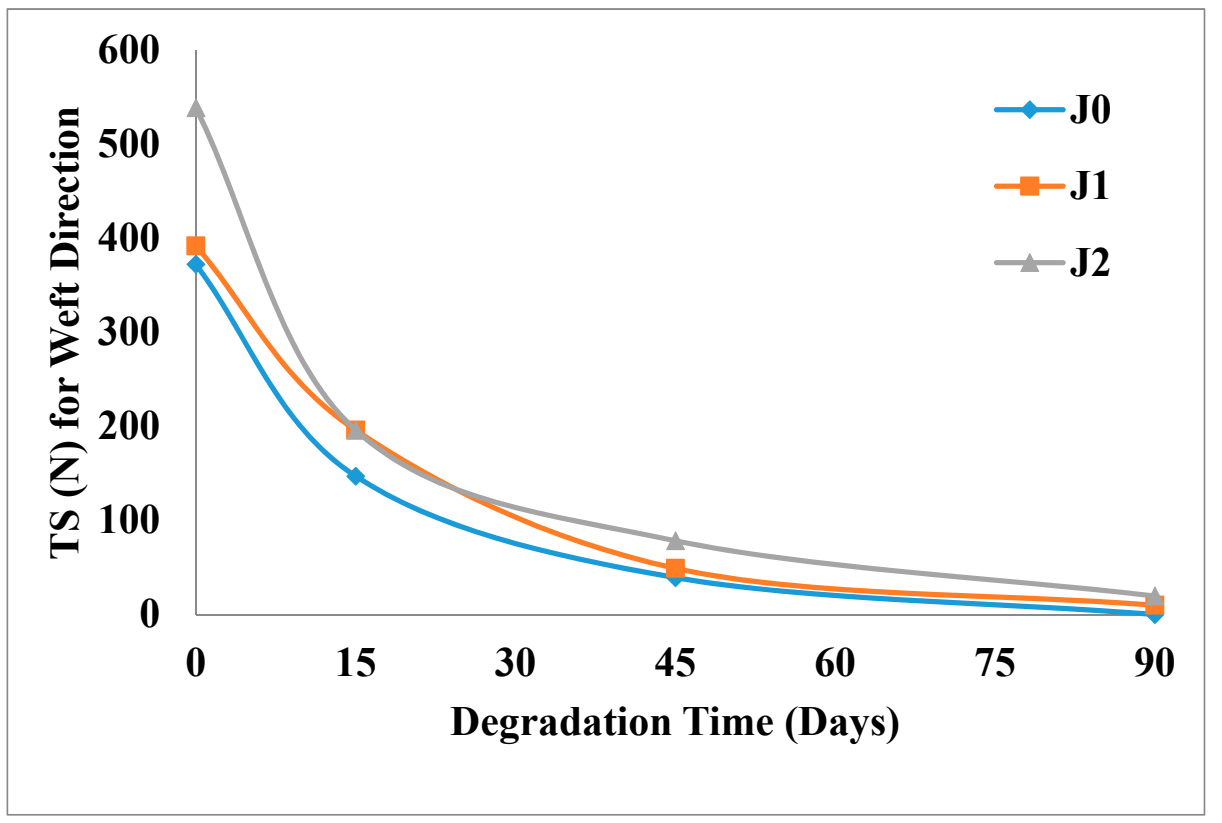

Figure 4. Loss of tensile strength of jute fabrics in weft direction during soil degradation.

For untreated jute fabric (J0), after 90 days, TS was not found due to complete degradation of the jute fabrics in soil. After 90 days, loss of TS found to be $97.5 \%$ and $96.4 \%$ for J1 and J2 fabrics in weft direction respectively.

Saha et al. [16] reported that after 42 days of soil degradation the loss of TS occurred $33.6 \%, 27.9 \%$, $23.2 \%, 17.9 \%, 8.2 \%$ and $8.0 \%$ for $0 \%, 5 \%, 10 \%, 15 \%, 20 \%$ and $25 \%$ resin treated jute fabrics respectively. For raw jute $33.6 \%$ TS loss was occurred and only $8.0 \%$ loss of TS occurred with $25 \%$ resin treatment after soil degradation. It is seen that after $42-45$ days, the loss of TS in Saha et al. (8.2\%) is lesser in the previous study than the present study (almost $80 \%$ ). This is due to the tensile property is not same for all jute fabrics, it depends on yarn count, fabric structures, picks per inch, ends per inch etc. It is also seen that the loss of TS for untreated jute was almost 34\% in [16] but it is almost $84 \%$ in current study, so the raw jute fabric properties are not same for the previous study and the current study. 
From the current study, it is also found that the loss of TS is protected in comparison to the untreated jute fabrics in both warp and weft directions. Moreover, the TS were found even after 90 days on the treated samples, where the untreated samples were completely degraded after 90 days. Therefore, the addition of bitumen emulsion in PE resin significantly improves the degradation properties of jute fabrics.

Jute is a hydrophilic biodegradable fiber, which has a very strong affinity to water, due to its $-\mathrm{OH}$ groups in the polymer chain. When buried in soil, the degradation accelerated due to water penetration into the jute fiber, microbial degradation may also occur. As a result, the mechanical properties of jute fiber decreased substantially. Nevertheless, the treated jute samples showed a better result than the untreated one. The untreated jute showed very poor durability in soil, as jute fiber is naturally biodegradable. After 15 days, the loss of TS was moderate, while after 45 days over $50 \%$ TS loss for all the samples was recorded. Finally, after 90 days, degradation was completed i.e., TS was almost zero. This was due to the natural degradation process of the fiber and with the increase of degradation time jute fiber also decayed.

The combined coating of bitumen emulsion and PE resin extended the degradation period of the treated fabrics beyond that of the untreated one. Bitumen emulsion has good anti-stripping, anti-rutting, and anti-microbial properties, which help to prevent the degradation of jute in soil. However, with the extension of the degradation period, the coating becomes weak and slowly decrease the bitumen and PE coating around the jute fibers as both polymers are biodegradable.

\subsection{Weight Loss by Soil Degradation}

The initial weight (GSM) of untreated jute fabric (J0) was $325.5 \mathrm{~g} / \mathrm{m}^{2}$. After soil burial, the weights were found to be 200, 100 and $0 \mathrm{~g}$ after 15, 45 and 90 days respectively. Similarly, initial weights of $\mathrm{J} 1$, and $\mathrm{J} 2$ samples were 417.42 and $556 \mathrm{~g} / \mathrm{m}^{2}$ respectively and after 15,45 and 90 days the weights were found to be $371.99,310,150 \mathrm{~g} / \mathrm{m}^{2}$ for J1 fabric, and $372,265,80 \mathrm{~g} / \mathrm{m}^{2}$ for J2 fabric respectively as shown in Figure 5. It was revealed that after 45 days $69.28 \%, 25.73 \%$, and $52.34 \%$ weight loss occurred for J0, J1, and J2 samples respectively, and after 90 days $100 \%, 64.06 \%$, and $85.61 \%$ weight loss occurred for J0, J1, and J2 samples respectively. Untreated jute fabric (J0) showed the highest loss of weight during soil degradation i.e., $100 \%$ degradation after 90 days.

On the other hand, J2 sample showed the least degradation after 90 days due to $10 \%$ bitumen emulsion and $20 \%$ resin content where the adhesion between fiber and the mixture of bitumen emulsion and resin was better than for other samples. Bitumen emulsion addition in PE resin enhances the lifetime durability of jute fabrics as shown in Figure 5 where untreated jute completely perished after 90 days. Figure $1 \mathrm{~d}$ shows the evidence of treated jute fabrics after 90 days of soil burial.

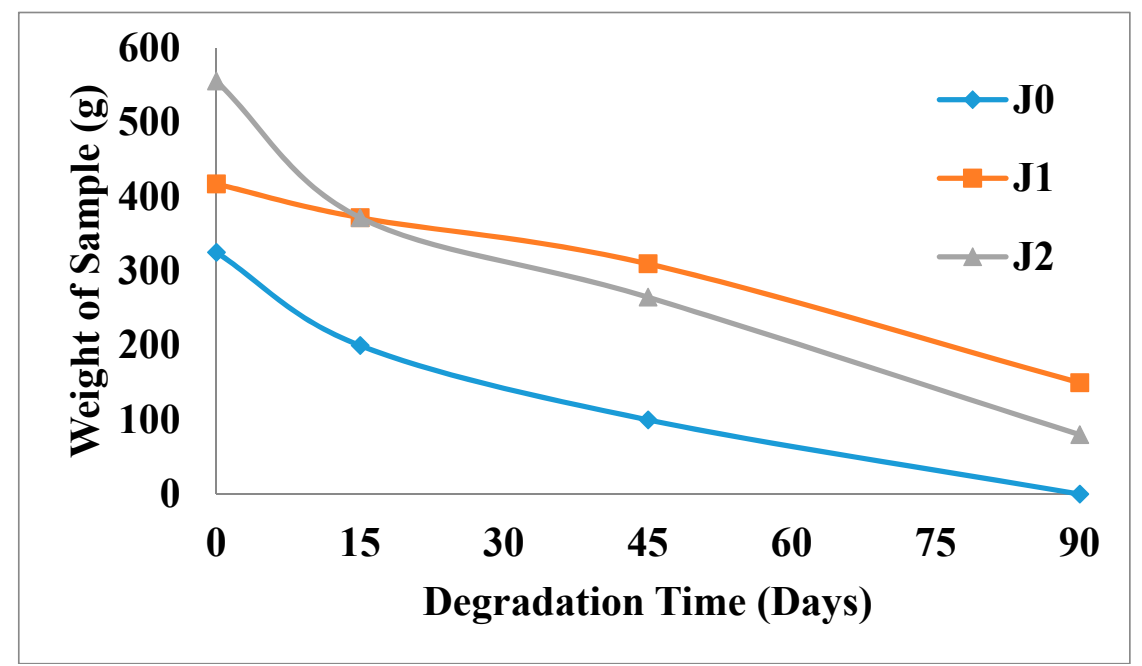

Figure 5. Weight loss of the jute samples during soil burial test. 
Normally, the price of PE resin per $\mathrm{kg}$ is five times greater than that of bitumen emulsion. Therefore, this could be a great achievement because only 20\% PE resin and 10\% bitumen emulsion was used. Thus, use of this combination may drastically reduce the total treatment cost, by substituting cheaper bitumen emulsion for PE.

\subsection{Moisture Regain and Moisture Content}

Figure 6 demonstrated that for J0 (untreated), J1 and J2 fabrics MR were 13.51\%, 12.50\% and $9.50 \%$ respectively and MC were $11.90 \%, 11.00 \%$ and $8.11 \%$ respectively. MR and MC reduced up to $29.68 \%$ and $31.85 \%$ respectively for $\mathrm{J} 2$ ( $10 \%$ bitumen emulsion $+20 \%$ PE resin) as compared to untreated jute samples. Thus, it was revealed that MR and MC decreased with the increase of PE resin percentage in the jute fabrics. This is happened due to the excellent coating of jute fibers by the mixture of bitumen emulsion and PE resin and these two hydrophobic polymers may block the hydroxyl group of jute fibers.

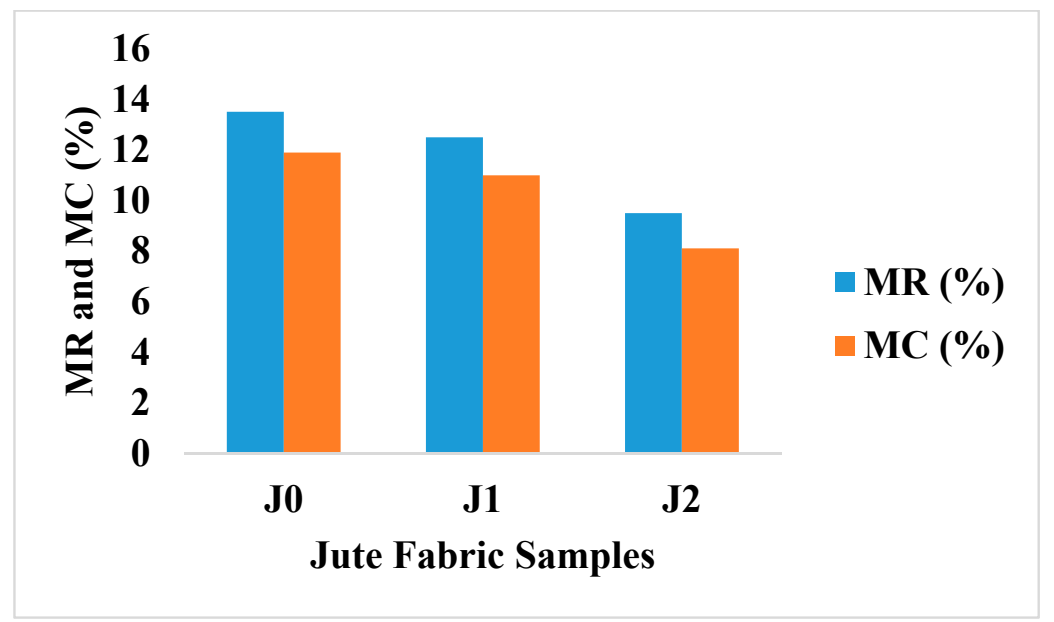

Figure 6. Moisture regain (MR) and moisture content (MC) of the jute fabrics.

\subsection{Water Uptake (\%)}

Figure 7 showed that water absorbency for J0, J1, and J2 samples was $68.5 \%, 60.8 \%$, and $38.2 \%$ respectively. Water absorbency abated with the accumulation of resin and bitumen in the fabrics and highest decreased of water absorbency was found to be $44.2 \%$ for $\mathrm{J} 2$ fabric $(10 \%$ bitumen emulsion and $20 \%$ PE resin) treated specimen as compared to the untreated one.

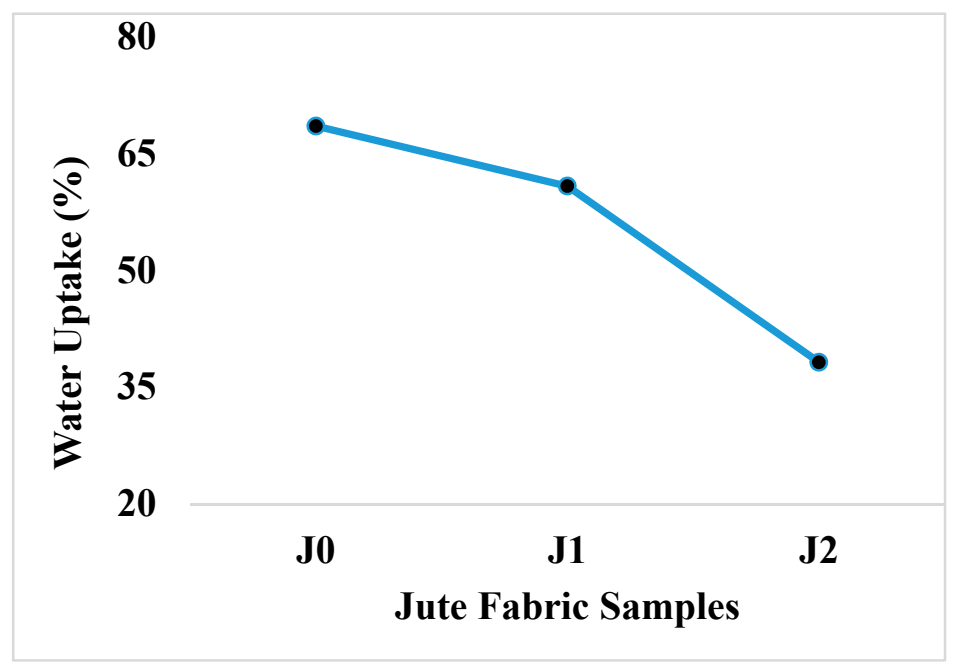

Figure 7. Water Uptake (\%) of jute fabrics. 
It was identified that hydrophilic property of the untreated specimen reduced and it became hydrophobic after the treatment. The polar -OH groups in jute built $\mathrm{H}$-bond by up taking water molecules which induced swelling in fibers. PE and bitumen emulsion are hydrophobic polymer that cross-linked with jute and made strong bonding with cellulose polymer chains and it provided a coating on the fabric surface which imparted the hydrophobic nature. The voids inside the fiber also filled by these polymers and protected water penetration into the jute fibers. Moreover, strong adhesion between jute and these polymer mixtures reduced the water uptake ability of the sample.

\subsection{Scanning Electron Microscopy (SEM)}

The treated and untreated surface morphology of jute fibers was evaluated by SEM. Figure 8a,c,e display the SEM images of untreated fabric surfaces at 30,50 and 100 times magnification and Figure $8 b, d, f$ show the SEM images of treated fabric surfaces of 30, 50 and 100 times magnification. The untreated fiber surface is free from polymer solution and has a smooth surface. The multi-cellular nature of the jute fibers is vividly observed whereas a rough surface is found for the treated sample. In each case, the treated sample is clearly more compact and dense. In addition, the treated sample appears to contain many polymer droplets. Thus, bitumen emulsion and PE resin treatment of jute demonstrated considerable change of morphology and topology of the fiber surface due to the good adhesion between the fiber and the polymer solution. In summary, the SEM observation clearly showed the difference between the untreated and treated surfaces of the jute fabrics.

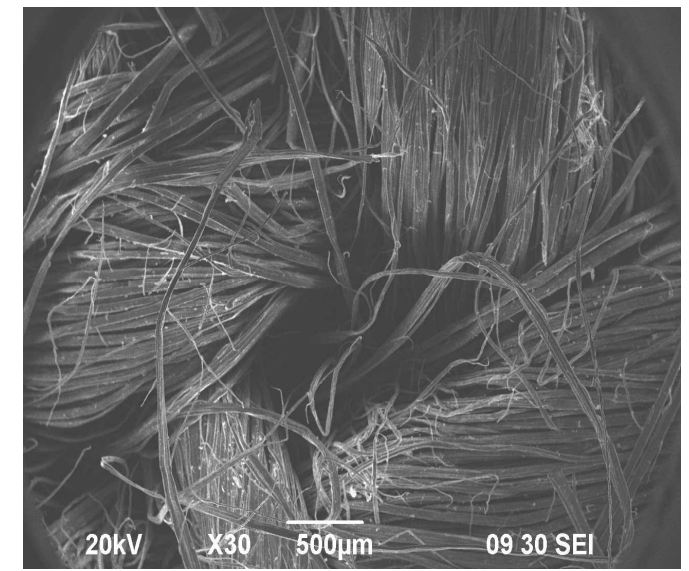

(a)

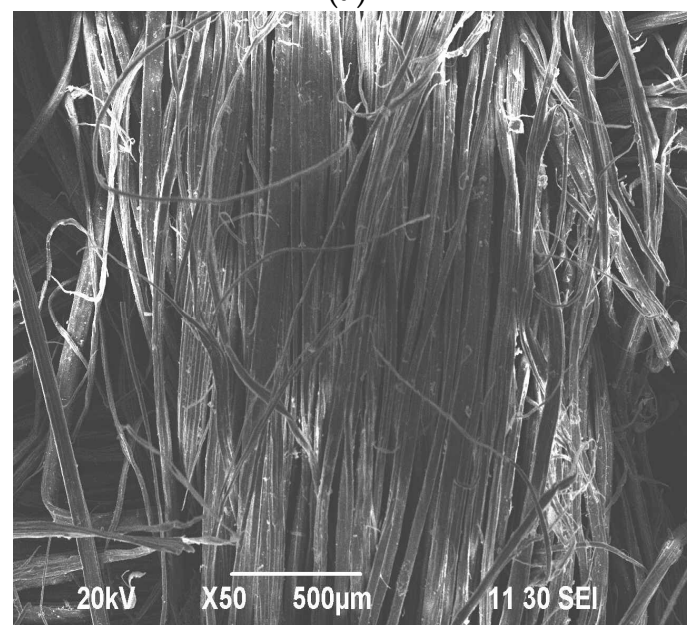

(c)

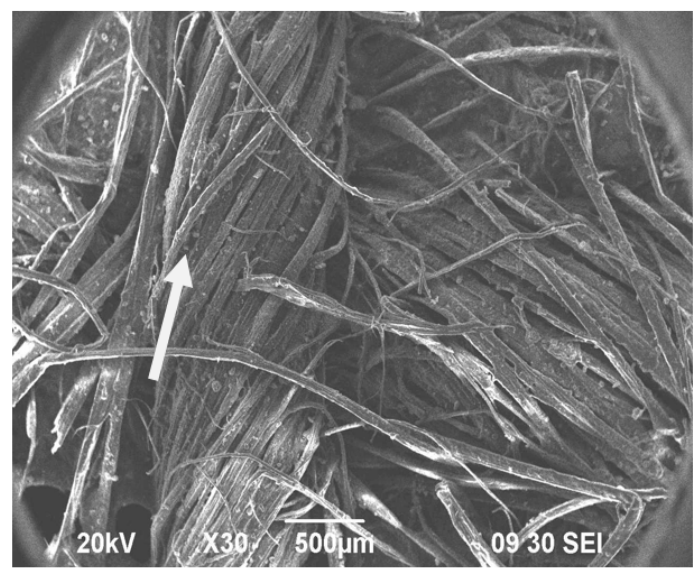

(b)

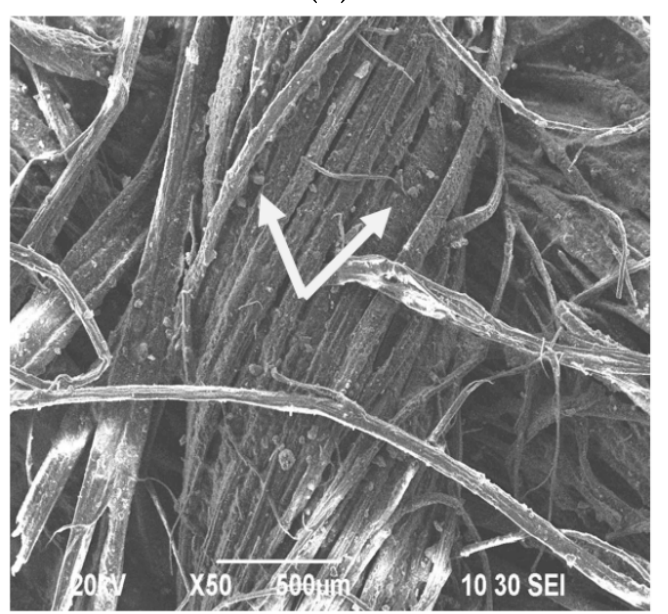

(d)

Figure 8. Cont. 


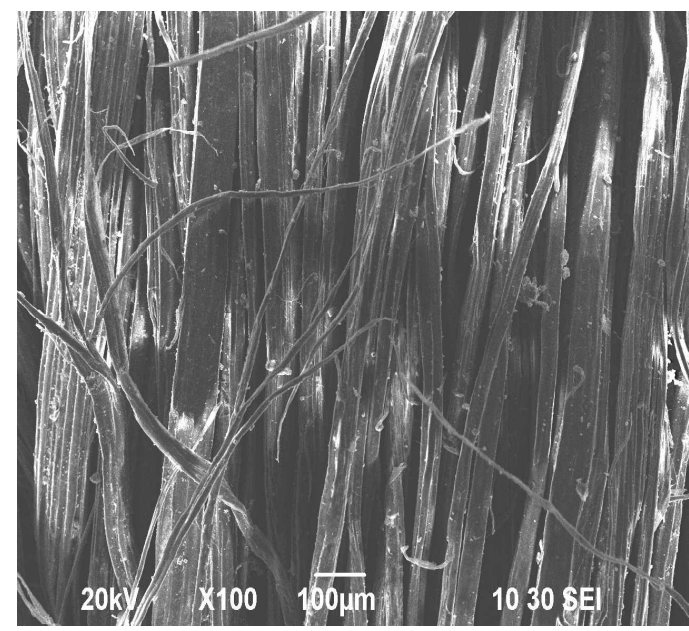

(e)

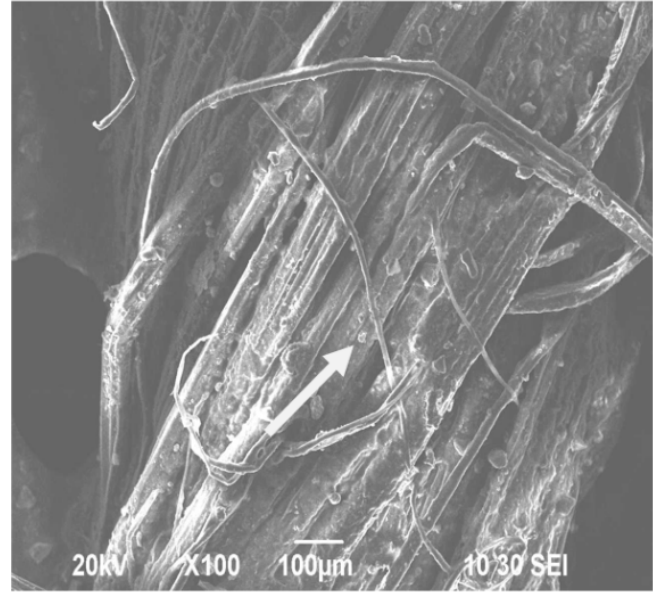

$(\mathbf{f})$

Figure 8. SEM images of jute fabric treated by bitumen emulsion and polyester resin mixture: (a) Untreated jute $(\times 30)$; (b) treated jute $(\times 30)$; (c) Untreated jute $(\times 50)$; (d) treated jute $(\times 50)$; (e) Untreated jute $(\times 100)$; (f) treated jute $(\times 100)$.

\section{Conclusions}

The present study demonstrated that treating the jute fabrics with the mixture of bitumen emulsion and polyester resin solution was a beneficial technique to ameliorate the physico-mechanical characteristics of jute by overcoming its some inherent drawbacks such as poor stability in a soil and water medium. The treatment also improved the tensile strength of jute fabrics significantly, in both warp and weft directions. Soil degradation tests revealed that treated samples retained their tensile strength for longer periods of exposure to soil but that the tensile strength of fabrics deteriorated with increased exposure time. The effect of biodegradation of jute increased with a longer burial period. Other properties such as moisture regain, moisture content and water absorbency were also found to be better after treatment. The scanning electron microscopy observations clearly demonstrated the difference between the treated and untreated surfaces. Finally, it could be concluded that the combined application of bitumen emulsion and polyester resin was better than only polyester resin treatment. This combination of treatments produced not only a better fabric but a cheaper one.

Author Contributions: M.A.K. conceived and designed the experiments; N.A. performed all the experiments; J.S. analyzed the SEM images; S.C.D. analyzed the data and wrote the paper; all the authors reviewed and edited the final paper.

Funding: This research received no external funding.

Conflicts of Interest: The authors declare no conflicts of interest.

\section{References}

1. Mishra, S.P. A Text Book of Fiber Science and Technology; New Age International Publishers: New Delhi, India, 2000; ISBN 978-81-224-1250-5.

2. Rankilor, P. Designing textiles into the ground. Text. Horiz. 1990, 2, 14-15.

3. Mazumdar, A.; Samajpati, S.; Ganguly, P.K.; Sardar, D.; Dasgupta, P.C. Swelling of jute: Heterogenety of crimp formation. Text. Res. J. 1980, 50, 575-578.

4. Stout, H.P. Handbook of Fiber Science and Technology; Lewin, M.M., Pearce, E.M., Eds.; Marcel Dekker Inc.: New York, NY, USA, 1985.

5. Ghosh, S.K.; Bhattacharyya, R.; Mondal, M.M. A review on jute geotextile-Part 1. Int. J. Res. Eng. Technol. 2014, 3, 378-386.

6. Das, S.C.; Nizam, M.E.H. Applications of fiber reinforced polymer composites (FRP) in civil engineering. Int. J. Adv. Struct. Geotech. Eng. 2014, 3, 299-309. 
7. Kafi, A.A.; Abedin, M.Z.; Beg, M.D.H.; Pickering, K.L.; Khan, M.A. Study on the mechanical properties of jute/glass fiber-reinforced unsaturated polyester hybrid composites: Effect of surface modification by ultraviolet radiation. J. Reinf. Plast. Compos. 2006, 25, 575-588. [CrossRef]

8. Pejic, B.M.; Kostic, M.M.; Skundric, P.D.; Praskalo, J.Z. The effects of hemicelluloses and lignin removal on water uptake behavior of hemp fibers. Bioresour. Technol. 2008, 99, 7152-7159. [CrossRef] [PubMed]

9. Rosa, M.F.; Chiou, B.S.; Medeiros, E.S.; Wood, D.F.; Williams, T.G.; Mattoso, L.H.; Orts, W.J.; Imam, S.H. Effect of fiber treatment on tensile and thermal properties of starch/ethylene vinyl copolymers/coir biocomposites. Bioresour. Technol. 2009, 100, 5196-5202. [CrossRef] [PubMed]

10. Khan, J.A.; Khan, M.A.; Islam, R.; Gafur, A. Mechanical, thermal and interfacial properties of jute fabric-reinforced polypropylene composites: Effect of potassium dichromate. Mater. Sci. Appl. 2010, 1, 350-357. [CrossRef]

11. Miah, M.J.; Khan, M.A.; Khan, R.A. Fabrication and characterization of jute fiber reinforced low density polyethylene based composites: Effects of chemical treatment. J. Sci. Res. 2011, 3, 249-259. [CrossRef]

12. Zaman, H.U.; Khan, M.A.; Khan, R.A.; Noor-A-Alam, M.; Bhuian, Z.H. Studies of the physico-mechanical interfacial, and degradation properties of jute fabrics/melamine composites. Int. J. Polym. Mater. 2012, 61, 748-758. [CrossRef]

13. Chubuike, O.M.; Ebele, C.C.; Ifeanyi, I.F.; Okwuchukwu, E.S.; Festus, O.E. Study on chemical treatments of jute fiber for application in natural fiber reinforced composites (NFRPC). Int. J. Adv. Eng. Res. Sci. 2017, 4, 21-26. [CrossRef]

14. Malenab, R.A.J.; Ngo, J.P.S.; Promentilla, M.A.B. Chemical treatment of waste abaca for natural fiber-reinforcement geopolymer composite. Materials 2017, 10, 579. [CrossRef] [PubMed]

15. Swain, P.T.R.; Biswas, S. Abrasive wear behavior of surface modified jute fiber reinforced epoxy composites. Mater. Res. 2017, 20, 661-674. [CrossRef]

16. Saha, J.; Das, S.C.; Rahman, M.; Siddiquee, M.A.B.; Khan, M.A. Influence of polyester resin treatment on jute fabrics for geotextile applications. J. Text. Sci. Technol. 2016, 2, 67-80. [CrossRef]

17. Types of Bitumen Emulsion-Uses, Advantages and Manufacture. Available online: https://theconstructor. org/transportation/bitumen-emulsion-types-uses-advantages/16375/ (accessed on 30 March 2018).

18. RAHA Bitumen Co. Available online: http://rahabitumen.com/bitumen-emulsion/ (accessed on 30 March 2018).

19. Bitumen Emulsions. Available online: http://www.bitumina.co.uk/bitumen-emulsions.html (accessed on 30 March 2018).

20. Moses, O.O. Investigation of performance of glass fiber impregnated with bitumen emulsion against reflective cracking. J. Civ. Environ. Eng. 2014, 4. [CrossRef]

21. Du, J.C.; Kuo, M.F.; Yeh, J.C. Properties of cement asphalt emulsion mortar for pavement. Adv. Mater. Res. 2013, 723, 466-473. [CrossRef]

22. Dash, S.B.; Panda, M. A study on use of natural fiber for improvement in engineering properties of dense graded bituminous mixes with coal ash. Transp. Dev. Econ. 2016, 2. [CrossRef]

23. Abtahi, S.M.; Sheikhzadeh, M.; Heijazi, S.M. Fibre-reinforced asphalt-concrete-A review. Constr. Build. Mater. 2010, 24, 871-877. [CrossRef]

24. Ali, N.; Chan, J.S.; Simms, S.; Bushman, R.; Bergan, A.T. Mechanistic evaluation of fly ash asphalt concrete mixtures. ASCE J. Mater. Civ. Eng. 1996, 8, 19-25. [CrossRef]

25. Bonica, C.; Toraldo, E.; Andena, L.; Marano, C.; Mariani, E. The effect of fibers on the performance of bituminous mastics for road pavements. Compos. Part B Eng. 2016, 95, 76-81. [CrossRef]

26. Toraldo, E.; Mariani, E.; Malvicini, S. Laboratory investigation into the effects of fibers on bituminous mixtures. J. Civ. Eng. Manag. 2015, 21, 45-53. [CrossRef]

27. Bueno, B.D.S.; da Silva, W.R.; de Lima, D.C.; Minete, E. Engineering properties of fiber reinforced cold asphalt mixes. J. Environ. Eng. 2003, 129, 952-955. [CrossRef]

28. Sever, K.; Sarikanat, M.; Seki, Y.; Erkan, G.; Erdogan, U.H. The mechanical properties of $\gamma$-methacryloxypropyl trimethoxy silane-treated jute/polyester composites. J. Compos. Mater. 2010, 44, 1913-1924. [CrossRef] 
29. Das, S.C.; Paul, D.; Siddiquee, M.A.B.; Islam, J.M.M.; Khan, M.A. Experimental investigation and analysis of mechanical behavior of jute fabric reinforced polyester composites. In Proceedings of the International Conference on Mechanical, Industrial and Energy Engineering, KUET, Khulna, Bangladesh, 26-27 December 2016; ICMIEE-PI-160-167.

30. Patel, R.B.; Patel, K.S.; Patel, R.N.; Patel, K.D. Thermal and mechanical properties of modified polyester resin and jute composites. Der Chem. Sin. 2014, 5, 47-54.

31. Fonseca, V.M.; Fernandes, V.J.; de Carvalho, L.H.; d'Almeida, J.R.M. Evaluation of the mechanical properties of sisal-polyester composites as a function of the polyester matrix formulation. J. Appl. Polym. Sci. 2004, 94, 1209-1217. [CrossRef]

32. Prasad, G.L.E.; Gowda, B.S.K.; Velmurugan, R. Comparative study of impact strength characteristics of treated and untreated sisal polyester composites. Procedia Eng. 2017, 173, 778-785. [CrossRef]

33. Munakaampe, G.M.; Kanyanga, S.B.; Myler, P.; Chizyuka, C.G. Response of natural sisal reinforced polyester composites to three-point and four-point bending. Procedia Manuf. 2017, 7, 327-332. [CrossRef]

34. Okonkwo, U.C.; Chukwunyelu, C.E.; Oweziem, B.U.; Ekuase, A. Evaluation and optimization of tensile strength responses of coir fibres reinforced polyester matrix composites (CFRP) using taguchi robust design. J. Miner. Mater. Charact. Eng. 2015, 3, 225-236. [CrossRef]

35. Islam, M.T.; Das, S.C.; Saha, J.; Paul, D.; Islam, M.T.; Rahman, M.; Khan, M.A. Effect of coconut shell powder as filler on the mechanical properties of coir-polyester composites. Chem. Mater. Eng. 2017, 5, 75-82. [CrossRef]

36. Balaji, V.; Senthil, V.K. Mechanical characterization of coir fiber and cotton fiber reinforced unsaturated polyester composites for packaging applications. J. Appl. Packag. Res. 2017, 9, 12-19.

37. Simonassi, N.T.; Pereira, A.C.; Monteiro, S.N.; Margem, F.M.; Rodriguez, R.J.; Deus, J.F.; Vieira, C.M.F.; Drelich, J. Reinforcement of polyester with renewable ramie fibers. Mater. Res. 2017. [CrossRef]

38. Devi, L.U.; Joseph, K.; Nair, K.C.M.; Thomas, S. Ageing studies of pineapple leaf fiber-reinforced polyester composites. J. Appl. Polym. Sci. 2004, 94, 503-510. [CrossRef]

39. Yogesh, M.; Hari, R.A.N. Study on pineapple leaves fiber and its polymer based composite: A review. Int. J. Sci. Res. 2017, 6, 799-807.

40. Das, S.C.; Islam, M.T.; Khan, M.A.; Mamun, M.A.A.; Mittro, B.K.; Saha, J.; Paul, D. Fabrication and mechanical characterization of PALF plain fabric reinforced polyester biocomposites. In Proceedings of the International Conference on Computer, Communication, Chemical, Materials and Electronic Engineering IC ${ }^{4} \mathrm{ME}^{2}-2017$, Rajshahi, Bangladesh, 26-27 January 2017; p. 55.

41. Dhakal, H.; Zhang, Z.; Richardson, M. Effect of water absorption on the mechanical properties of hempfibre reinforced unsaturated polyester composites. Compos. Sci. Technol. 2007, 67, 1674-1683. [CrossRef]

42. Mwaikambo, L.; Bisanda, E. The performance of cotton/kapok fabric-polyester composites. Polym. Test. 1999, 18, 181-198. [CrossRef]

43. Das, S.C.; Paul, D.; Siddiquee, M.A.B.; Saha, J.; Khan, M.A.; Islam, J.M.M. Study on the mechanical properties of non-woven glass fiber reinforced polyester composites. In Proceedings of the International Conference on Computer, Communication, Chemical, Materials and Electronic Engineering $\mathrm{IC}^{4} \mathrm{ME}^{2}-2017$, Rajshahi, Bangladesh, 26-27 January 2017.

44. Das, S.C.; Paul, D.; Islam, J.M.M.; Khan, M.A. Effect of gamma radiation on the mechanical properties of PET felt reinforced polyester composites. In Proceedings of the International Conference on Mechanical, Industrial and Energy Engineering 2016, KUET, Khulna, Bangladesh, 26-27 December 2016.

45. Swain, P.K.; Das, M.; Nayak, P.L. Biodegradation studies of chitosan-polycaprolactone (PCL) nanocomposite in soil burial test. Middle-East J. Sci. Res. 2015, 23, 253-258.

46. Hu, J. BS 4784 Determination of Commercial Mass of Consignment of Textiles Part-I. In Fabric Testing, 1st ed.; Woodhead Publishing Series in Textiles; Elsevier: Cambridge, UK, 2008; p. 33.

47. Hu, J. BS 3449 Testing the Resistance of Fabric to Water Absorption (Static Immersion Test). In Fabric Testing, 1st ed.; Woodhead Publishing Series in Textiles; Elsevier: Cambridge, UK, 2008; pp. 233-234.

(C) 2018 by the authors. Licensee MDPI, Basel, Switzerland. This article is an open access article distributed under the terms and conditions of the Creative Commons Attribution (CC BY) license (http://creativecommons.org/licenses/by/4.0/). 